ERJ

Engineering Research Journal

Faculty of Engineering

Menoufiya University

\title{
MODELING COMMON RAIL FUEL INJECTION SYSTEM IN DIESEL ENGINES
}

\author{
Safwat A. Wilson \\ Mechanical Power Engineering Dept. \\ Faculty of Engineering Menoufiya University, Shebin El-Kom, Egypt
}

\begin{abstract}
In the present work, a mathematical model is developed to simulate and predict the performance of electronically controlled fuel injection system for diesel engines at different operating conditions. The fuel system employs common rail techniques which characterized by symmetrical fuel injection for all engine cylinders and injection pressure beyond $1 \mathrm{k}$ bar. The resultant spray configuration and the availability of multiple injections each cycle leads to achieve significant improvement in combustion efficiency and emissions. The mathematical model introduced in the present work includes the simulation of control signals from electronic control unit "ECU". The model considered the injection timing and firing order when dealing with multiple injectors. Besides, the model includes mathematical simulation of electromagnet power solenoid valves, kinematics of pump plungers due to cam rotation, dynamics of valves and needles motion and finally the flow of fuel through the entire system elements taking into consideration the compressibility effect. The results of the present model are compared with experimental and the available mathematical models to validate the present model. Comparison shows fair agreement. The model shows the great importance of solenoid response in injection timing. The model is proven to be a good tool for exploring the capability of electronically controlled common rail injection system to perform different injection strategies as well as its ability to run with different fuel types. The model can serve also as sub-model in sophisticated CFD codes to simulate realistic combustion process in Diesel engines.

يقدم هذا البحث نموذج رياضي لتمثيل ودر اسـة أداء نظم الحقن ذات التحكم الإلكترونى الخاصـة بمحركات الديزل

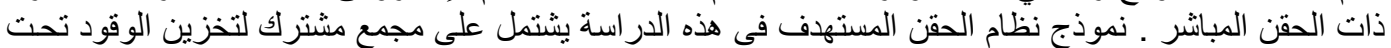

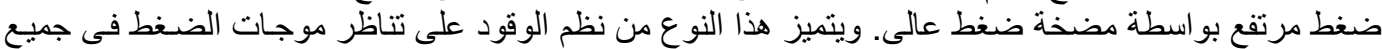
حو اقن الوقود مما يضمن معايرة دقيقة للوقود لجميع الاسطوانات مقارنة بالنظم الهيدروليكية التقليدية. كما أن التحكم

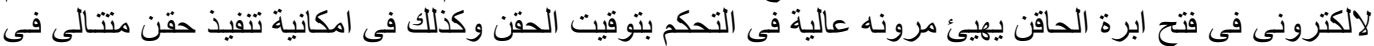

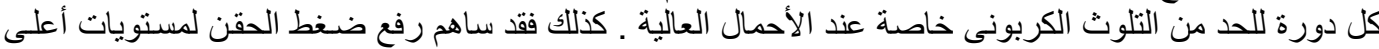

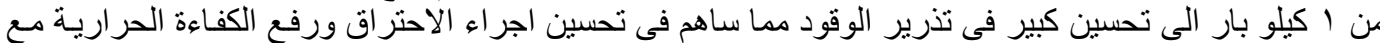

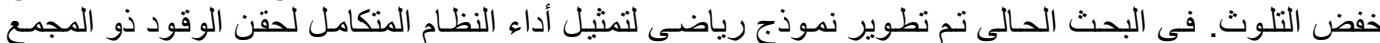

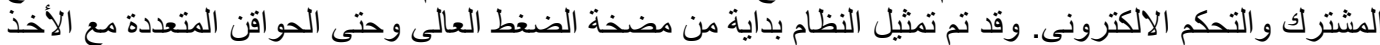

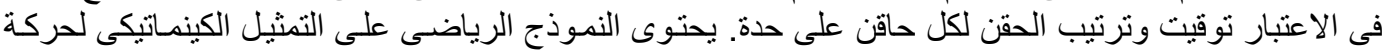

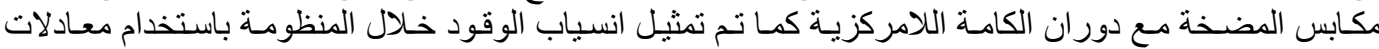

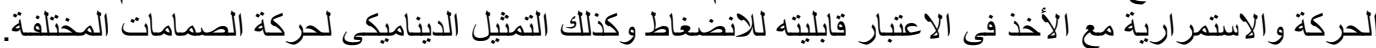

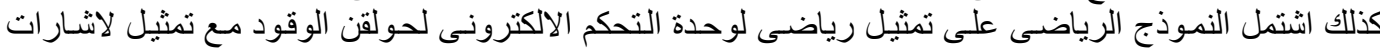

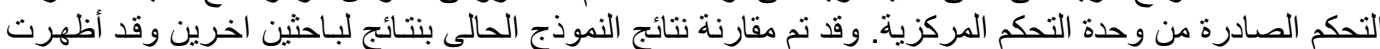

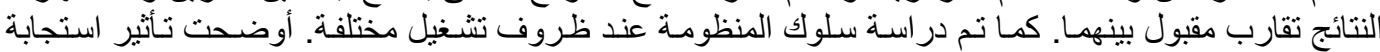

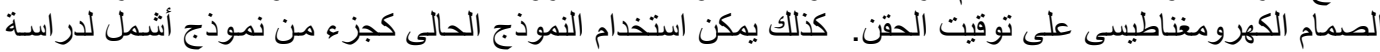
اجر اء الاحتر اق فى محركات الديزل.
\end{abstract}

Keywords: electronic fuel injection, common rail, Diesel engines, mathematical model,

\section{INTRODUCTION}

The modern version of common rail fuel injection system employs electronic control unit instead of hydro-mechanical system in older versions [1]. This enables a great flexibility to achieve the proper injection timing at different operating conditions. In addition, the system can easily perform pilot injection, split injection or even multiple injection each cycle. The dowel period between successive injections can be controlled also. Both the injection 
pressure and duration are controlled via ECU to permit precise adjustment for injection rate and total amount of fuel injected during the cycle. The system is applied on two stroke engines [2] as well as in conventional four stroke engines [3], in Diesel engines [4-6] alongside with gasoline direct injection "GDI" [7-9] albeit it used in Diesel engines earlier. Numerous investigations were carried out to unveil the characteristics of engines when running with such systems. Some work, focused on studying the structure of resultant spray when using two stages injection techniques [10-12]. Atomization characteristics and spray interaction with turbulent flow inside combustion chamber when using common rail injection system were studied [13-15]. Their results show clear correlation between fuel injection system and resultant spray. This appears clearly in rapid disintegration of spray droplets near the nozzle. Others are interested in combustion characteristics and emissions. Reitz et.al.[16-21] tried to exploit the capabilities of electronic controlled injection systems to perform multiple injection in single cylinder Diesel engine. They implemented this technique by reprogramming the $E C U$ to produce fast successive control signals to injector's solenoid within certain period. They also tried to change the dwell period between active signals. The resultant is multiple sprays during combustion period. Experiments show great improvement based on this technique in terms of specific fuel consumption and emissions especially at full load condition. They also implemented multiple injections by using biodiesel blend as alternative fuel [22]. At high load, they observed significant decrease in particulate matter and $\mathrm{CO}$ with increasing the percentage of biodiesel in blended fuel, especially when using multiple injection strategy. But on other hand they recorded slight increase in NOx at this operating condition. Important trial to optimized combustion process in diesel engine was carried out by Boulouchos et. al [23]. They combined turbocharged direct injection "DI" diesel engine equipped with Miller system and common rail fuel injection system. They prove that using common rail injection system with variable turbine geometry offers great flexibility to optimize engine configuration for its entire operating range and no exhaust gas recirculation "EGR" was needed at part load to reduce NOx emissions. The preliminary improvement in engines performance encourages the researchers to unveil the effect of injection system parameters on combustion process. These parameters include the effect nozzle hole size and their number on heavy duty diesel engines [24]. They found that compromise between emissions and $B S F C$ performance could be achieved when decreasing hole size and using fewer number of holes. Other injection parameters like injection rate and style (direct or indirect) are studied [25]. Their results indicate that, in direct injection (Unit injector) there is some limitation to achieve ultra-short injection duration due to control valve response. While in indirect injection principles (common rail) don't have such limitations. Furthermore, decreasing injection duration with fixed injection pressure leads to increase the total duration of heat release and soot increases at retarded timings.

As reviewed previously, great leap in diesel engines performance within relatively short period is achieved. This comes mainly with the introduction of electronically controlled fuel injection system specially the common rail system. Therefore, subjecting the system to in-depth study is essential to explore its capability and what it offers at different operating conditions. For this purpose, several attempts were made to simulate the modern electronically controlled fuel injection system in different versions. Hayat et. al. [26] present model for somewhat primitive version of electronically controlled injection system called Combination Electronic Unit Pump "CEUP" which depends on controlling inlet fuel to high pressure pump electronically, beside conventional hydro-mechanical injector and high pressure lines are employed. They focused on the pressure waves travelling through the pressure line. Therefore, they examined four different approaches to represent wave motion. They concluded that the viscous damping wave equation predicts more accurately. Thereafter, they used the same model to identify the effect of fuel factor on flow through CEUP pressure line [27]. In their work, they used diesel fuel and rapeseed methyl ester. Common rail injection system, which is more advanced, has been studied recently by Bingqi et. al [28]. They used experimental test bench to measure the main injection parameters at different operating conditions. Furthermore, they developed numerical simulation by using commercial code called Advanced Modeling Environment for performing Simulations of engineering systems "AMESim". The model is employed to predict fluctuations in main injection quantities when using pilot injection strategy. But, there is still one reservation on their work. It represented by using single branch (pressure line and injector) to represent injection process for four cylinders engine. So, the injector implemented four successive injections each cycle.

Finally, this work is a step forward to achieve more realistic and complete mathematical model for simulating modern Diesel engine cycle. In the following, the physical process and mathematical model required for simulating the injection system are introduced and discussed briefly. 


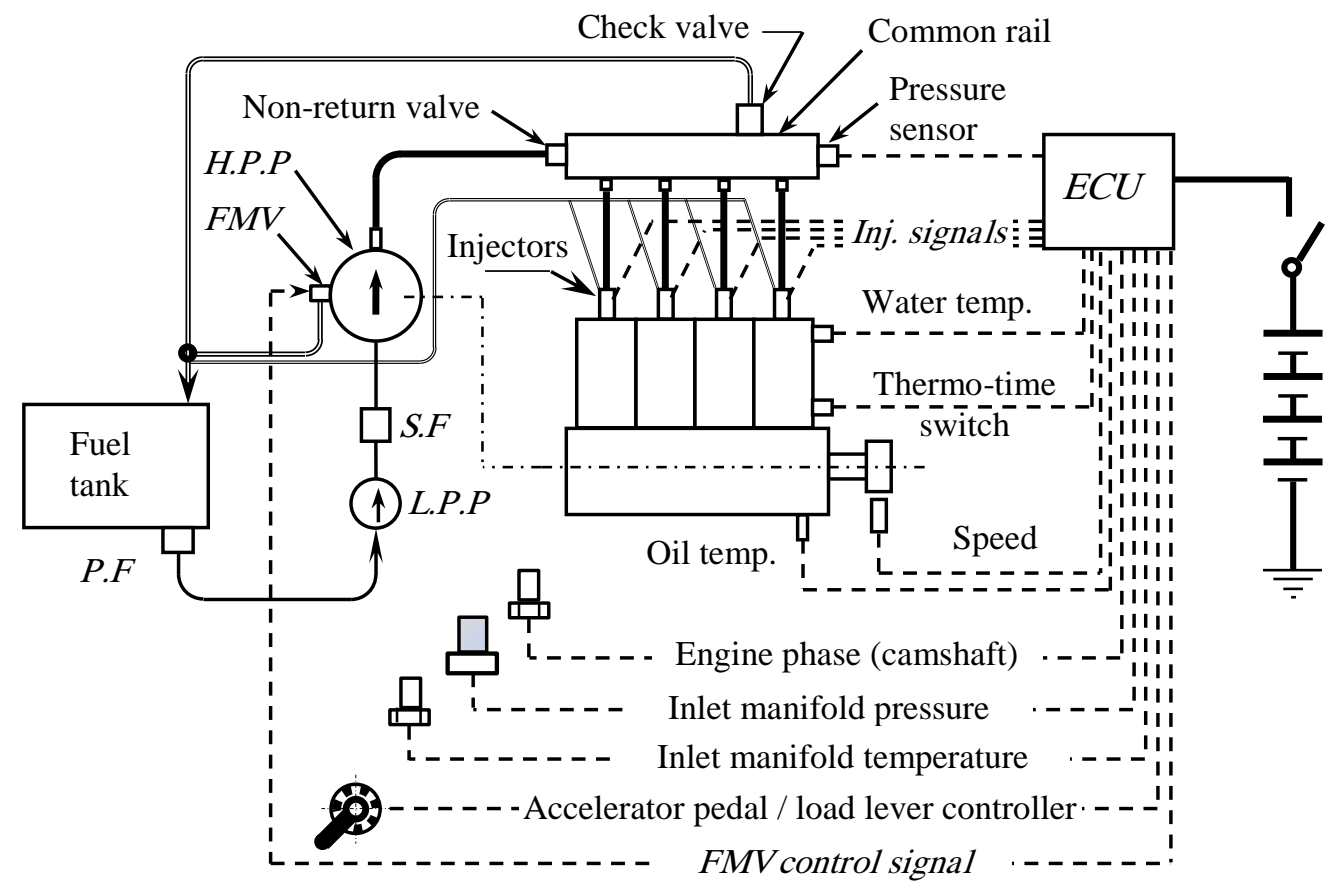

Figure 1 Layout of common rail fuel injection

\section{MATHEMATICAL MODEL}

In present work, a complete mathematical model is proposed to simulate the behavior and performance of electronically controlled version of common rail fuel injection system for direct injection Diesel engines. The model includes the kinematics of moving parts, dynamics of fluid flow, electronic control signals and characteristics of electromagnetic field applied on solenoid valves used to control the injection process. The system under consideration is illustrated in fig. 1. It contains hydrodynamic system represented by pumps, common rail, high pressure lines and injectors. The system also includes electromagnetic actuators as solenoid valves used to control the fuel flow as well as the injection quantity required per cycle per cylinder, and finally neural system which controls all the vital processes of the injection system. It includes input signals from sensors, electronic control unit "ECU" which conducts calculations to assign the proper timing for injection process and send the control signals to specified solenoid valve of each injector.
1 : Pump plunger
4 : Fuel metering valve
2 : Eccentric cam
5 : High pressure line
3 : Inlet line
6 : Delivery valve

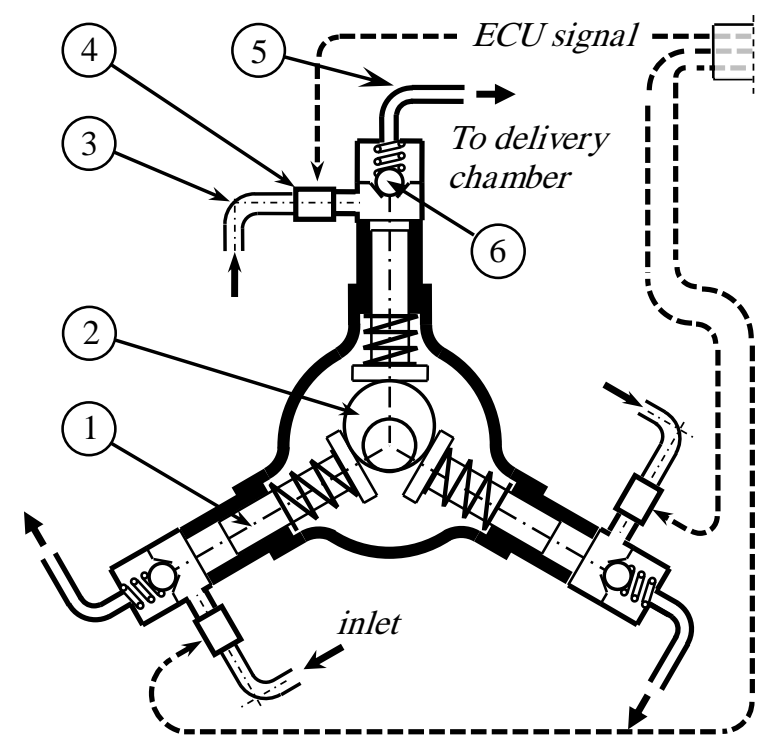

Figure 2 Layout of high pressure pump 


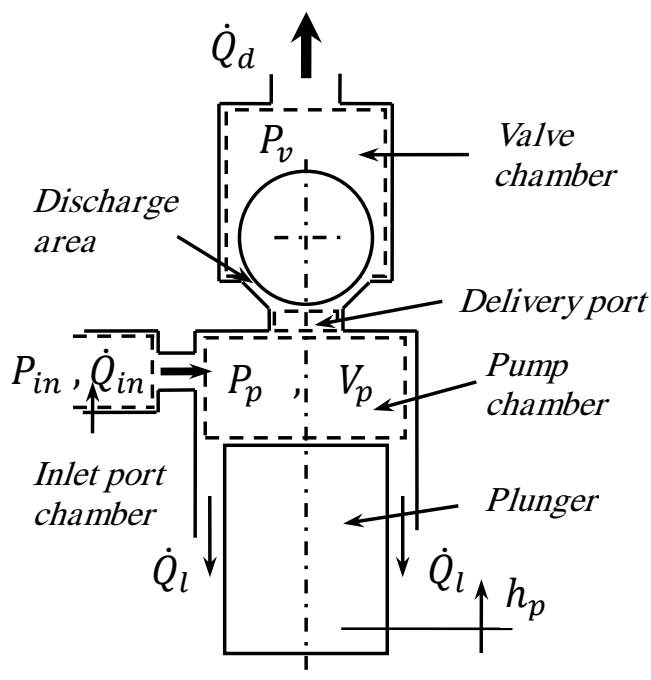

Figure 3 High pressure pump chambers and ports

\subsection{Pump side}

High pressure, positive displacement pump is used to generate compressed fuel flow and store it in suitable space called common rail. The details of the high pressure pump are illustrated in fig. 2. Most designs contain three active pumping elements as shown in the figure, in spite of other configurations may be used. Details of each individual pump assembly are illustrated in fig. 3 . When eccentric cam rotates, the pump plunger moves accordingly and displaced the fuel inside the pump barrel. If the inlet valve is open, the major part of displaced volume return from inlet valve until the fuel metering valve " $F M V "$ closed (see fig. 2) and real fuel compression process begins. The fuel metering valve is actuated via electric solenoid valve and controlled via electronic control unit (ECU) signal. Therefore, applying the principle of conservation of mass all over the pump chamber states that, the net change in fuel volume is equal to the rate of fuel flow into the pump chamber, out to the delivery chamber, leakage from plunger/barrel clearance and finally the rate of volumetric change in pump chamber due to plunger motion as follows.

$$
\frac{d V_{p}}{d t}=\dot{Q}_{i n}-\dot{Q}_{v}-\dot{Q}_{l}-\dot{V}_{p}
$$

For homogenous isotropic fluid, Bulk modulus of elasticity for liquids subjected to volumetric strain as a result of local pressure change is given as follows.

$$
K=V \frac{d P}{d V}=a^{2} \cdot \rho
$$

Then, instantaneous pump pressure becomes as follows.

$$
\frac{V_{p}}{K} \frac{d P_{p}}{d t}=\dot{Q}_{i n}-\dot{Q}_{v}-\dot{Q}_{l}+\dot{V}_{p}
$$

The details of each term in equation (3) are mentioned and discussed clearly in the following.

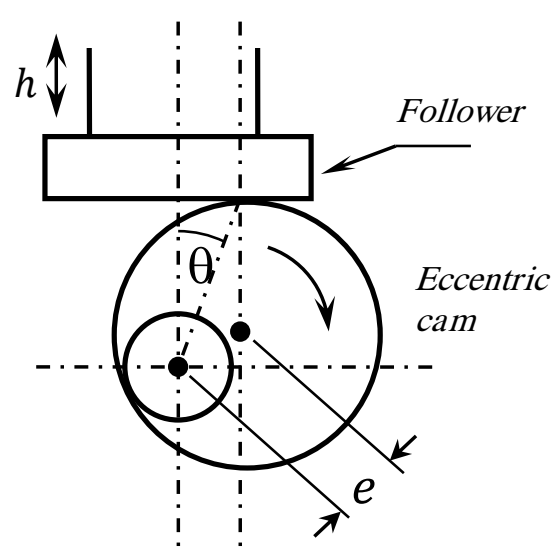

Figure 4 Plunger motion due to eccentric cam rotation

Starting with the kinematics of moving parts, the instantaneous plunger lift with respect to cam shaft rotation is illustrated in fig. 4. The plunger lift $h_{p}$ and its velocity $v_{p}$ are given as follows.

$$
\begin{aligned}
& h_{p}=e \cdot(1-\cos \theta) \\
& v_{p}=\omega \cdot e \cdot \sin \theta
\end{aligned}
$$

So, the corresponding volumetric change in pump chamber becomes.

$$
\dot{V}_{p}=v_{p} \cdot A_{p}
$$

The quantity of fuel entering pump barrel through inlet port is calculated as follows.

$$
\dot{Q}_{i n}=c_{d} A_{i} \sqrt{\frac{2}{\rho_{f}}} \frac{P_{i}-P_{p}}{\sqrt{\left|P_{i}-P_{p}\right|}}
$$

Inlet port area $A_{i}$ opens and closes according to the load and speed of the engine, where $E C U$ receives signals from the engine sensors and calculates the proper timing to close the inlet fuel port during the compression stroke. Taking into consideration that this process is not responsible for metering the amount of fuel injected to cylinder or even the injection timing but it just decreases the parasite load of the high pressure pump. The closing timing of inlet port is then calculated as follows. Signal from load control lever sensor is send to $E C U$ representing the load ratio $\left(l_{r}\right)$ which is the ratio between the current engine power relative to the maximum power 
could generate. It also indicates to the current amount of fuel injected to the amount of fuel required at full load. Thereafter, the effective plunger stroke is then calculated. Accordingly the cam angle at which the effective stroke begins is then calculated as follows.

$$
\theta_{i p}=\cos ^{-1}\left(1-\frac{h_{o}}{e}\left(1-l_{r}\right)\right)
$$

Where $h_{o}$ is the effective plunger stroke at no load condition where the required fuel is kept at minimal level. The value of $h_{o}$ is determined based on engine design, fuel properties and operating conditions as follows.

$$
\frac{h_{o}}{2 e}=f\left[\left(\frac{V_{s}}{V_{p}}\right)\left(\frac{\rho_{\text {air }}}{\rho_{f}}\right)\left(\frac{\eta_{v o}}{(A / F)_{o}}\right)\right]
$$

The previous equation indicates that, $h_{o}$ is proportion to volumetric efficiency at idling speed $\eta_{v o}$ and the reciprocal of air to fuel ratio at no load condition $(A / F)_{o}$. From details in fig.5, the effective stroke at no load condition becomes.

$$
s_{e o}=2 e-h_{o}
$$

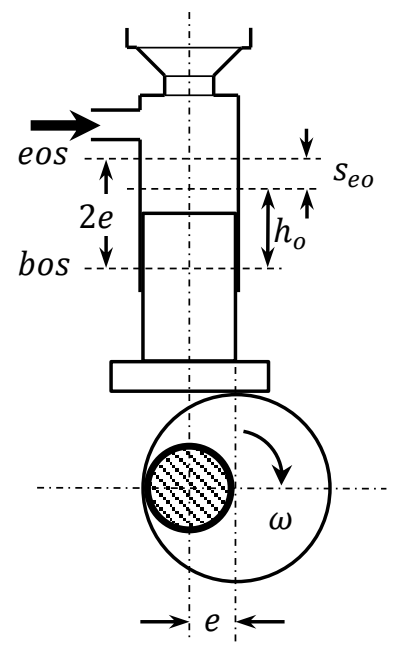

Figure 5 Relation between effective stroke and plunger position.

The camshaft sensor sends signals to ECU continuously representing the instantaneous position of the camshaft and consequently the instantaneous position of the pump plunger is then assigned. When the crank angle signal $\theta$ reaches the calculated value of $\theta_{i p}$ then $E C U$ send its signal to fire the solenoid of fuel metering valve ' $F M V$ ', which in turn closing the inlet port. By the end of stroke, $E C U$ terminates the control signal to $F M V$ allowing the inlet port to reopen for next stroke. The area of inlet port becomes cam angle dependent as follows.
For $\theta \leq \theta_{i p} \geq \theta_{\text {eos }}$ then $A_{i}=\frac{\pi}{4} d_{i}^{2}$

For $\theta>\theta_{\text {ip }}<\theta_{\text {eos }}$ then $A_{i}=0$

The logic diagram representing $F M V$ timing is shown in fig. 6.

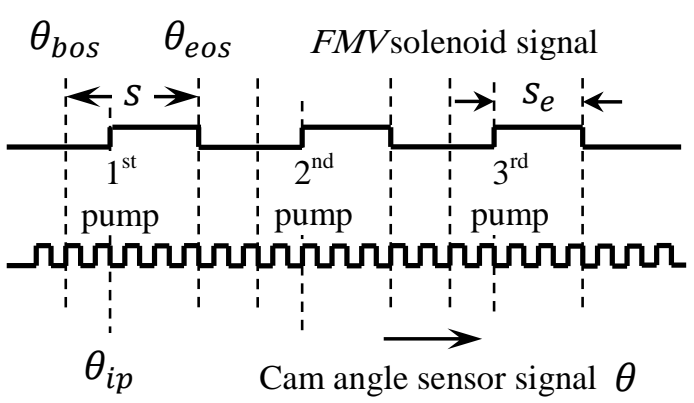

Figure 6 Logic diagram for FMV timing

The quantity of fuel delivered through delivery valve is calculated as follows.

$$
\dot{Q}_{v}=C_{d} A_{v} \sqrt{\frac{2}{\rho_{f}}} \frac{P_{p}-P_{v}}{\sqrt{\left|P_{p}-P_{d}\right|}}
$$

When pressure inside pump chamber reaches the opening pressure of the delivery valve, fuel flows through the delivery port directly to the valve chamber according to pressure difference and spring force as shown in fig. 7. The instantaneous valve position is then calculated from the following equation of motion.

$$
\begin{aligned}
m_{d} \frac{d^{2} Z}{d t^{2}}+C_{d} \frac{d Z}{d t} & +k_{d}\left(Z+Z_{o}\right) \\
& =A_{v}\left(P_{p}-P_{d}\right)
\end{aligned}
$$

Where, $m_{d}$ is the effective mass of delivery valve. It includes the mass of delivery valve ball and third of spring mass [29]. When delivery valve ball begins to move, a conical cross section area is then created between ball and its seat " $A_{c}$ " as shown in fig. 8. So, fuel in pump chamber passes through delivery port area " $A_{p}$ " and then through " $A_{c}$ " before entering delivery chamber. The effective discharge area controlling the flow is the minimum cross section area of both as follows.

$$
\begin{aligned}
& A_{c}=\pi z \cdot \sin \left(2 \theta_{S}\right)\left[r+\frac{Z}{2} \cdot \cos \left(\theta_{S}\right)\right] \\
& A_{p}=\frac{\pi}{4} d_{v}^{2} \\
& \therefore A_{v}=\min \left\{A_{v}, A_{p}\right\}
\end{aligned}
$$




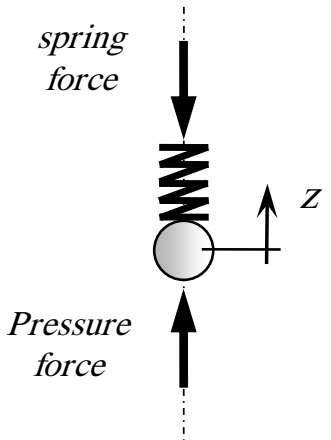

Figure 7 Forces acting on delivery valve

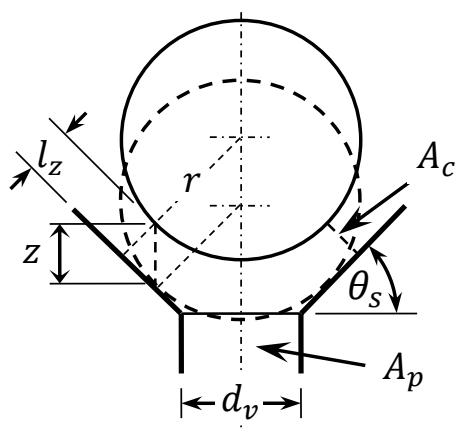

Figure 8 Discharge area during valve ball motion

\subsection{Valve chamber}

Fuel accumulated in valve chamber finds its way to the delivery chamber to merge with other fuel flow coming from other pump branches as shown in fig. 9. Applying the continuity principles, the volumetric change in fuel volume inside the valve chamber is equal to the differential flow rate between the inlet flows " $\dot{Q}_{v}$ " and outlet to the delivery camber " $\dot{Q}_{d}$ ". Considering the volumetric strain of fuel with pressure as in eq.(2), the instantaneous pressure becomes as follows.

$$
\frac{d p_{v}}{d t}=\frac{K}{V_{v}}\left(\dot{Q}_{v}-\dot{Q}_{d}\right)
$$

\subsection{Delivery chamber}

The fuel delivered from pump units enter delivery chamber in order to unify the pump outlet to common rail. Pulsated flow of fuel issued from pump units as well as the outlet to common rail pressure line change the pressure inside the delivery chamber as follows.

$$
\frac{d P_{d}}{d t}=\frac{K}{V_{d}}\left(\sum_{i=1}^{i=3} \dot{Q}_{d, i}-\dot{Q}_{r l}\right)
$$

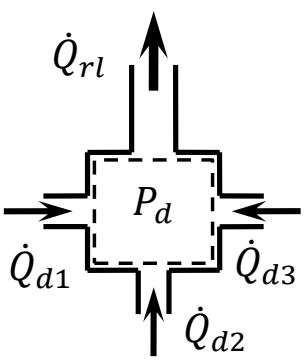

Figure 9 Flow through delivery chamber

\subsection{High pressure line}

The importance of pressure lines not being a carrier of the fuel but also of being a transmitter of the pressure waves, which in turn affects the injection characteristics. So accurate modeling is needed to simulate the flow of fuel. In present model, the fuel velocity and pressure is needed, so continuity and momentum equation are employed as well as the bulk modulus of elasticity eq.(2) to account the effect of compressibility. The flow is treated as time dependent, one dimensional and compressible flow. The governing equations are as follows.

\section{Continuity:}

$$
\frac{\partial \rho}{\partial t}+\frac{\partial \rho u}{\partial x}=0
$$

\section{Momentum:}

$$
\frac{\partial u}{\partial t}+u \frac{\partial u}{\partial x}=-\frac{1}{\rho_{f}} \frac{\partial P}{\partial x}+v_{f} \frac{\partial^{2} u}{\partial x^{2}}
$$

\section{Boundary conditions:}

The boundary conditions at both sides of the high pressure line are assigned as follows.

\section{Pump/Rail line}

At pump side

$u_{t, 0}=\dot{Q}_{r l} / A_{\text {pipe }}$

$P_{t, 0}=P_{d}(t)$

At common rail side

$u_{t, L}=\dot{Q}_{i-c r} / A_{\text {pipe }}$

\section{Rail/Injector line}

At common rail side

$u_{t, 0}=\dot{Q}_{o-c r} / A_{\text {pipe }}$

At injector side

$u_{t, L}=\left(\dot{Q}_{i l}+\dot{Q}_{\text {in }}\right) / A_{\text {pipe }}$ 
The non-linear differential equations $(19,20)$ are solved together numerically by using finite different scheme. Staggered grid system is used in present discretization process as shown in fig. 10.

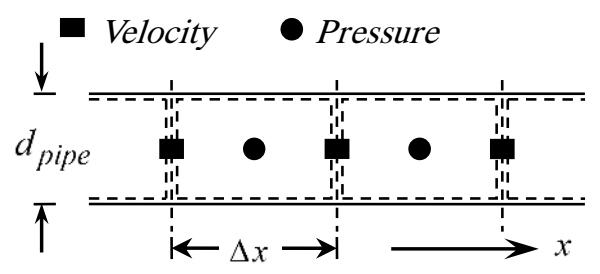

Figure 10 Construction of grid and cells used in numerical treatment.

\subsection{Common rail}

Common rail stores the fuel at high pressure in order to feed the injectors with their needs of fuel. The common rail is tube like in shape with feeding port from high pressure pump and several output lines to injectors (fig 11). It equipped with non-return valve, pressure limiter valve and pressure sensor. The volume of common rail must be large enough to damp pressure waves coming with inlet fuel and to keep the pressure fluctuations in minimum level. These fluctuations come from the pulsating nature of the fuel flow rate during the injection periods. Accordingly, the conservation of fuel inside the common rail is then applied as follows..

$$
\frac{d P_{c r}}{d t}=\frac{a^{2} \rho}{V_{c r}}\left(\dot{Q}_{i-c r}-\sum_{t=0}^{t_{c y c l e}} \dot{Q}_{o-c r}(t)\right)
$$

Where,

$$
\dot{Q}_{i-c r}=\rho_{f} A_{p} u_{i-c r}
$$

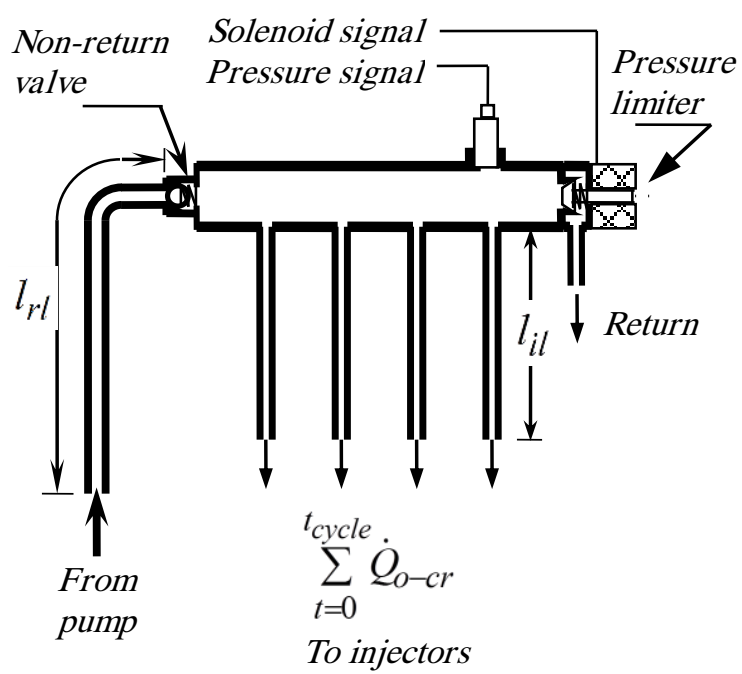

Figure 11 Details of common rail and high pressures lines

\subsection{Injector}

One of the most important parts in electronic controlled common rail fuel injection system is the injector. It is completely different from the conventional hydraulic fuel injection system. It depends on electrically controlled solenoid valve to perform accurate and precise injection timing and rate rather than the pressure waves. Besides, it introduces the availability of performing pilot and multiple injection process with great flexibility. The injector is fed by fuel from common rail via injection lines. The fuel is then branched in two different paths as shown in fig. 12. The first one inters the so called plunger control chamber through narrow orifice (about $0.24 \mathrm{~mm}$ diameter [28]). The cumulative fuel inside the plunger control chamber prevents needle valve from motion. The relatively larger plunger diameter than the needle diameter as well as the spring force contributes to secure the tightening of needle valve on its seat. When solenoid valve is fired, (via ECU signal) the armature is then attracted and pulling the ball valve. This allows fuel in plunger control valve to discharge rapidly causing the pressure to fall. Fuel in second branch goes directly to needle chamber. Pressure at needle chamber is then acts on needle valve and lifts it against spring force and low control chamber pressure. This allows the injection process to start with highest possible response. The details of injector modeling are given as follows.

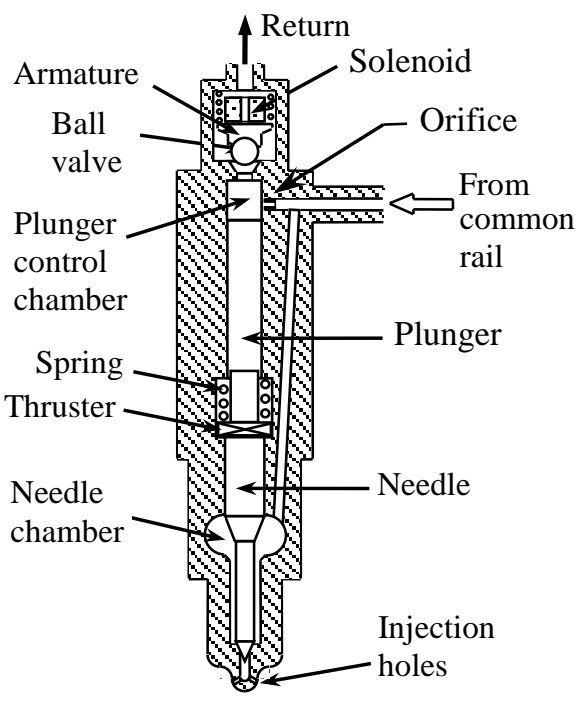

Figure 12 Injector details.

\subsubsection{Solenoid valve}

Solenoid valve is used to control injection process in terms of timing and period. It used not only in diesel injectors but also in SIE injectors and injecting liquid or even gaseous fuel [30]. Although in case of diesel engine, It consists of a coil and spring loaded armature. The armature has a ball valve to open or 
close the control chamber port. The circuit driver of solenoid appears in fig. 13. In order to start injection, the following process is considered. At the proper injection timing, ECU sends TTL signal to fast electronic switch. The circuit is then closed and electric current from main power source begins to flow. Corresponding magnetic field is then built up in the solenoid coil. Accordingly magnetic force is generated and attracts the armature against its spring force with little aid of pressure force exerted on the valve ball as shown in fig. 14 .

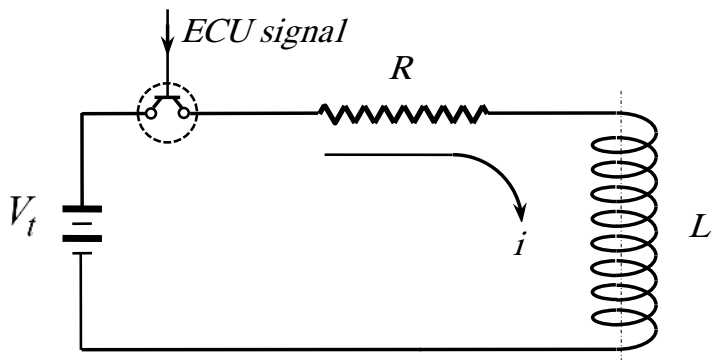

Figure 13 Circuit driver for solenoid valve

The main factor affecting magnetic force is the current. Which in turn is governed by the resistance $R$ and impedance comes from the self-induced emf in solenoid coil. The instantaneous change in current is calculated from the following equation.

$$
V_{t}=i \cdot R+L \frac{\partial i}{\partial t}+i \frac{\partial L}{\partial Z_{a}} \cdot \frac{d Z_{a}}{d t}
$$

The spatial change in the inductance $d L / d Z_{a}$ returns to the shrinkage in air gap between solenoid and armature during its motion which in turn increases the permeability as follows [31].

$$
L=N^{2} \mu_{o} A\left(\frac{1}{a_{g}-Z_{a}}\right)
$$

Magnetic force must be strong enough to snatch immediate response for armature motion. This force depends mainly on the current flowing through the driver circuit and the spatial change in inductance as follows [31].

$$
F_{m a g}=\frac{1}{2} i^{2} \frac{\partial L}{\partial Z_{a}}
$$

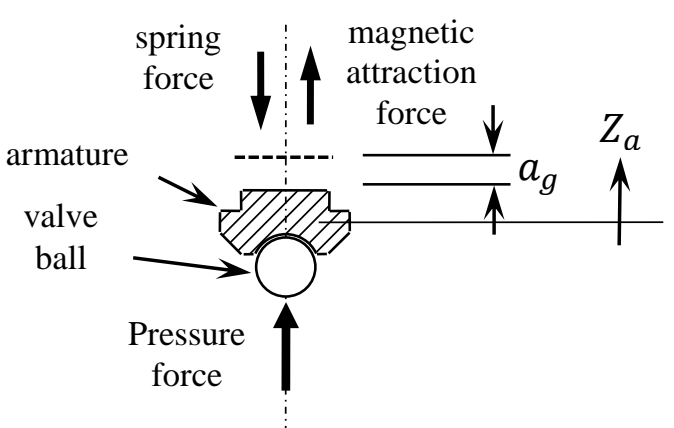

Fig. 14 Forces acting on solenoid armature
Taking into consideration the pressure force on both valve sides, the seat and upper limiter reaction forces, thereafter, the instantaneous armature displacement is calculated as follows.

$$
\begin{aligned}
m_{a} \frac{d^{2} Z_{a}}{d t^{2}}+k_{a}\left(Z_{a o}+Z_{a}\right) & \\
= & F_{m a g}+F_{p}+F_{s}-F_{l}
\end{aligned}
$$

Where, pressure force $F_{p}$ acting on the valve ball is calculated as follows.

$$
F_{p}=A_{c v}\left(P_{c c}-P_{c v}\right)
$$

Other forces affecting valve motion comes from the sudden contact between valve body with both seat and stoke limiter. This generates counter reaction forces and causes the valve to renounce. The reaction forces of both seat and upper stroke limiter of the armature is calculated according the dynamic concept appears in fig. 15.

\section{Valve/seat interaction:}

$$
\begin{aligned}
& \text { If } Z_{a}<0 \text { then, } F_{s}=-\left(k_{s} Z_{a}\right) \\
& \text { If } Z_{a} \geq 0 \text { then, } F_{s}=0
\end{aligned}
$$

Valve/upper limit interaction:

$$
\begin{aligned}
& \text { If } Z_{a}>Z_{a . \max } \text { then, } \\
& F_{l}=k_{l}\left(Z_{a}-Z_{a . \max }\right) \\
& \text { If } Z_{a} \leq Z_{a . \max } \text { then, } F_{l}=0
\end{aligned}
$$

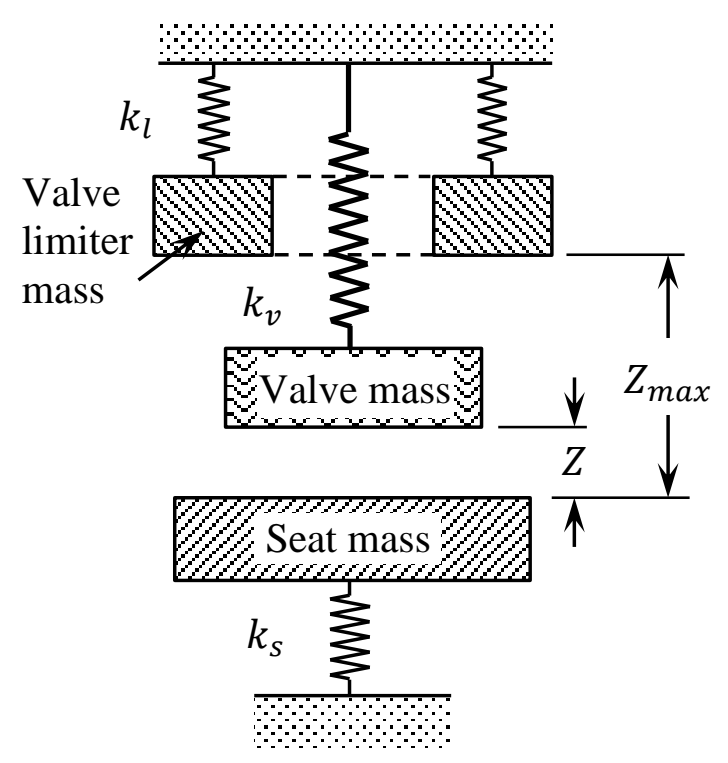

Figure 15 Dynamic representation of valve motion 


\subsubsection{Injection control unit}

This unit consists mainly from plunger control chamber, feeding port, outlet port to control valve chamber beside the control valve itself as shown in fig 16. According to the role of plunger control chamber in injection process which discussed previously, the instantaneous change of pressure inside the chamber could be represented by applying the continuity equation as follows.

$$
\frac{d P_{c c}}{d t}=\frac{a^{2} \rho}{V_{c c}(t)}\left(\dot{Q}_{i l}-\dot{Q}_{c v}+A_{i p} \frac{d Z_{n}}{d t}\right)
$$

Where, $\dot{Q}_{i l}$ is the volumetric flow rate of fuel feeding the chamber through the orifice. Its value depends on the differential pressure across the orifice as follows.

$$
\dot{Q}_{i l}=c_{d} A_{o . i l} \sqrt{2 / \rho_{f}} \frac{P_{i l}-P_{c c}}{\sqrt{\left|P_{i l}-P_{c c}\right|}}
$$

Accordingly, the volumetric flow rate out to control valve chamber $\dot{Q}_{c v}$ is calculated as follows.

$$
\dot{Q}_{c v}=c_{d} A_{c v} \sqrt{2 / \rho_{f}} \frac{P_{c c}-P_{c v}}{\sqrt{\left|P_{c c}-P_{c v}\right|}}
$$

Where, $A_{c v}$ is the instantaneous discharge area of control valve. It depends mainly on the valve position " $Z_{a}$ " obtained by solving equation of motion eq (24). This valve has the same design as delivery valve appears in fig. 8, but not the same dimensions. Therefore, the value of $A_{c v}$ is then calculated exactly as in eq (14) except for replacing delivery valve lift " $Z$ " by control valve position " $Z_{a}$ " and port diameter " $d_{v}$ " by " $d_{c v}$ ". The third term in eq (28) represents the volumetric change in plunger control chamber due to the plunger/needle motion. Thus, the instantaneous plunger control chamber volume is assigned as follows.

$$
V_{c c}(t)=V_{c c}(t-\Delta t)+\frac{\pi}{4} d_{i p}^{2}\left(Z_{a}(t)-Z_{a}(t-1)\right)
$$

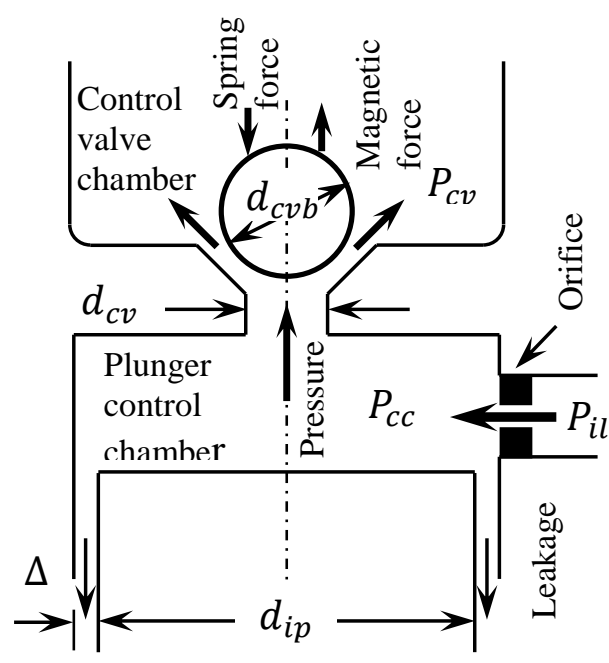

Figure 16 Injection control unit

\subsubsection{Needle chamber}

It contains cavity with certain volume and needle valve. The needle is mechanically linked with the plunger of the control chamber as shown in fig. 12 and has smaller diameter. The net resultant forces applied on needle/plunger assembly govern its motion as follows.

$$
m_{n} \frac{d^{2} z_{n}}{d t^{2}}+k_{n}\left(z_{n o}+z_{n}\right)=F_{p}+F_{s}-F_{l}
$$

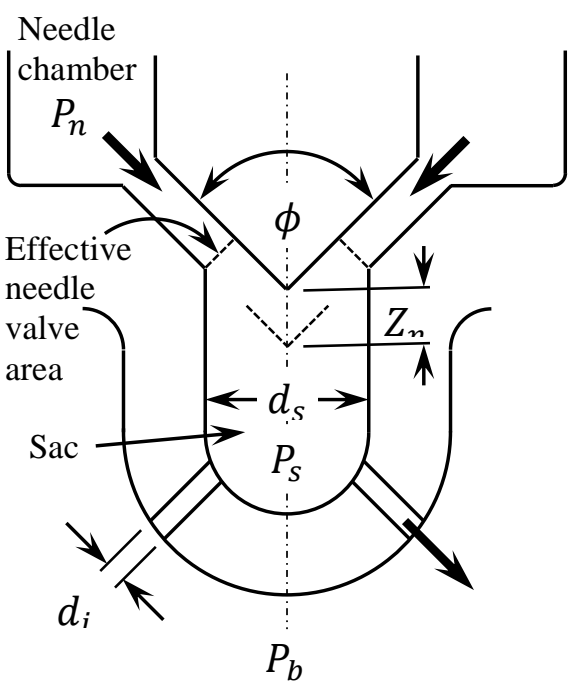

Figure 17 Details of injector nozzle

When needle departs its seat, discharge area begins to create, allowing the fuel in needle chamber to flow into sac (distribution hole) as shown in fig. 17, and then to outside through injection holes. The instantaneous effective needle valve area varies with respect to needle lift as follows.

$$
A_{n}=\frac{\pi Z_{n} \cdot \sin \phi}{2 \cdot \cos (\phi / 2)}\left[2 d_{S}-Z_{n} \sin \phi\right]
$$

Applying continuity equation on needle chamber, the instantaneous pressure is then calculated as follows.

$$
\frac{d P_{n}}{d t}=\frac{a^{2} \rho}{V_{n}(t)}\left[\dot{Q}_{i n}-\dot{Q}_{o}+A_{n} \frac{d Z_{n}}{d t}\right]
$$

Where, $V_{n}(t)$ is the instantaneous volume of needle chamber. While, $\dot{Q}_{\text {in }}$ is the volume flow rate feeding the needle chamber from injection line. It can be expressed as follows.

$$
\dot{Q}_{i n}=A_{i l} u_{i l, L}
$$

Where, $A_{i l}$ is the cross section area of high pressure line feeding needle chamber and $u_{i l, L}$ is fuel velocity at the end of fuel line (injector side). On the other hand, the amount of fuel leaving needle chamber to outside is calculated as follows. 


$$
\dot{Q}_{o}=A_{e f f} \sqrt{2 / \rho_{f}} \frac{P_{n}-P_{b}}{\sqrt{\left|P_{n}-P_{b}\right|}}
$$

Equation (36) takes into account the flow through the sac before injection to the ambient. This appears clearly in $A_{\text {eff }}$ term. Where it comes when applying continuity on sac chamber as follws.

$$
A_{e f f}=\frac{\left(c_{d n} A_{n}\right)\left(c_{d h} A_{h}\right)}{\sqrt{\left(c_{d n} A_{n}\right)^{2}+\left(c_{d h} A_{h}\right)^{2}}}
$$

Therefore the sac pressure is then becomes as follows.

$$
P_{s a c}=\frac{\left(c_{d n} A_{n}\right)^{2} P_{n}+\left(c_{d h} A_{h}\right)^{2} P_{b}}{\left(c_{d n} A_{n}\right)^{2}+\left(c_{d h} A_{h}\right)^{2}}
$$

Where, $c_{d n}$ is the discharge coefficient through the area between needle and its seat and $c_{d h}$ is the coefficient of discharge through the injection holes [32].

$$
c_{d h}=1 / \sqrt{1.5+\frac{l_{h}}{d_{h}\left(1.14+2 \log \frac{k}{d_{h}}\right)^{2}}}
$$

Where, $k$ is the absolute roughness of inner hole surface. In case of $1 \mathrm{~mm}$ hole length, $1 \mu \mathrm{m}$ absolute roughness and hole diameter $160 \mu \mathrm{m}$, the discharge coefficient is almost 0.7

\subsection{Leakage treatment}

Leakage through the clearance between moving parts is treated considering Couette flow due to very low velocity. Parts exposed to leakages are illustrated in Figures 3 and 16. When moving part velocity is taken into account, the discharge leakage is calculated as follows [33].

$$
\dot{Q}_{l}=\left(\frac{\Delta P}{12 \mu_{f}} \Delta^{2} l \mp \frac{1}{2} u_{p}\right) \pi d \Delta
$$

where, $u_{p}$ is the relative velocity between moving parts and the sign indicates the flow direction. Total amount of fuel leaks through the clearance of both plunger/bush and needle/bush is obtained by integrating previous equations with respect to time as follows:

$$
Q_{l(\text { total })}=\int\left(\dot{Q}_{l}\right)_{\text {plunger }} \cdot d t+\int\left(\dot{Q}_{l}\right)_{\text {needle }} \cdot d t
$$

The normalized leakage per pump cycle is calculated as follow.

$$
\bar{Q}_{l(\text { total })}=\frac{\dot{Q}_{l(\text { total })}}{\frac{\pi}{4} d_{p}^{2} \cdot S \times n_{p}}
$$

\section{SOLUTION PROCEDURES}

The proposed model described above represents nonlinear physical process occurs inside electronically controlled HPCR system. The model based on strongly coupled set on conservation equations in differential form. So, finite difference technique is employed to solve these equations numerically. At the beginning of solution procedure, the pressure inside pump barrel, pressure lines, common rail, injector's chambers are assumed as residual pressure. This value is considered as initial rail pressure. With the progress of the solution steps, the assumed values are then updated continuously. Iteration process continues each time step and from one cycle to another until convergence is achieved. The time step used in numerical treatment is short enough to capture pressure waves travelling through pressure lines and ensure numerical stability as well. This is achieved when Courant number becomes less than the unity [34] as follows

$$
C=(|u|+a) \frac{\Delta t}{\Delta x} \leq 1
$$

In present work, cam shaft step is considered as 0.001 degree which analogues to time step equal to the following.

$$
\Delta t=\frac{\Delta \theta}{6 N}
$$

For $750 \mathrm{rpm}$ cam shaft rotation, time step becomes $2.22 \times 10^{-7} \mathrm{~s}$. The time step becomes shorter at higher speed. Therefore, the grid size is assigned to meet the stability criterion represented in Courant number, eq(44).

The model is programmed in Fortran code to facilitate the study of HPCR behavior at different operating conditions.

\section{MODEL VALIDATIONS}

The output of the present model is compared with results of Bingqi et. al [28]. In their work, they developed numerical model by using commercial software environment "AMESim" to simulate the injection process of HPCR system. They validated their model by comparing the model results with recorded experimental data. They used Bosh type HPCR system in experimental work. The technical data of the fuel system are given in table (A1). The experimental configurations of this test case are 750 rpm camshaft speed of high pressure pump, 1350 bar rail pressure and $1.2 \mathrm{~ms}$ injection signal. Comparison shows fair agreement between present model results and their experimental and prediction model. As shown in Fig 18, the present model can capture the 
same level of pressure and frequency of fuel fluctuated inside the common rail as in experimental work. On the other hand, the rate of fuel injection during each injection cycle is compared with experimental and simulation data of the same test case as shown in fig. 19. Comparison shows fair agreements in terms of injection duration and rate. In spite sharper profile at the beginning of injection is obtained in present model, it proves to be capable to predict and simulate the injection process for such injection system accurately.

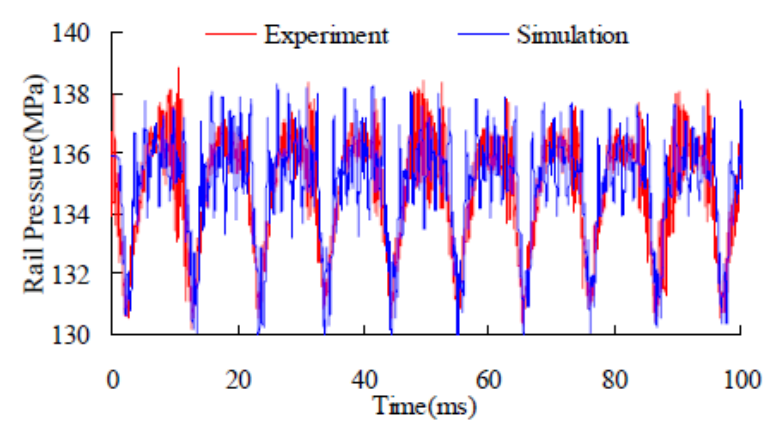

(a) Experimental \& simulation of [28]

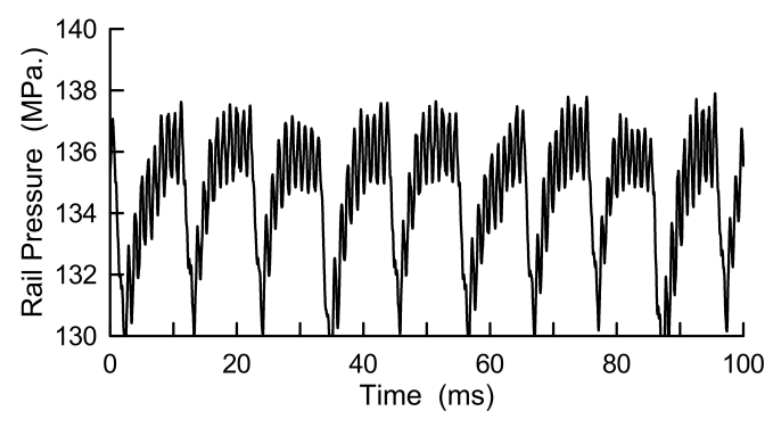

(b) Present model

Figure. 18. Instantaneous rail pressure @ 750 rpm pump speed and 1350 bar rail pressure.

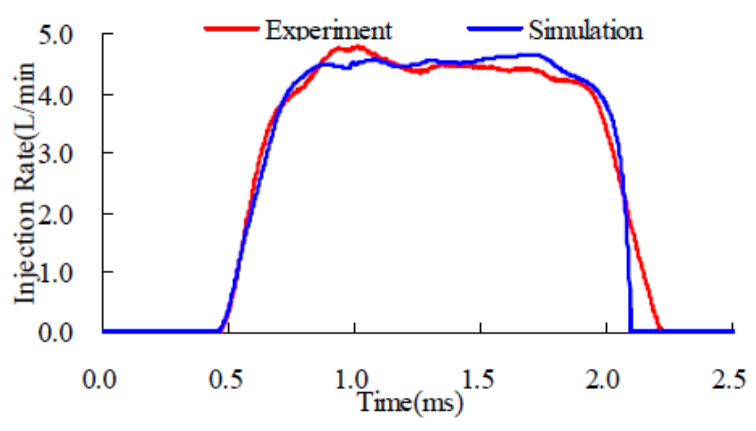

(a) Experimental \& simulation of 28]

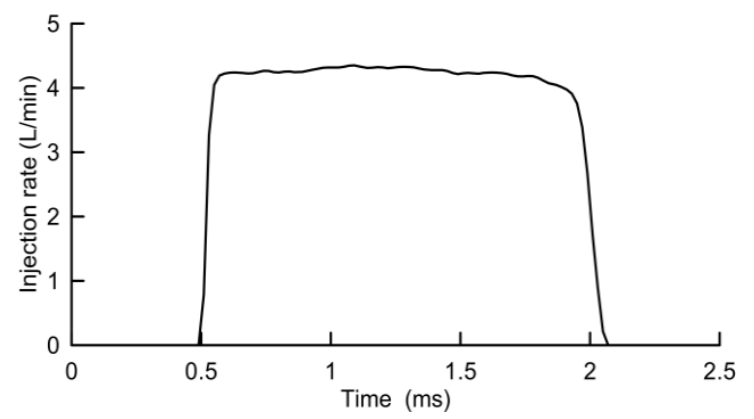

(b) Present model

Figure 19 Injection rate

\section{RESULTS AND DISCUSSION}

In the following the model is employed to predict the behavior of electronically controlled common rail injection system at certain operating conditions. The injection system, which is the same as in [28] is considered to be compatible for four cylinder engine. Therefore, the system contains four pressure lines with their injectors. At the first case, the model is employed to examine the effect of injection duration on the quantity of fuel injected per cycle per cylinder. The pump rotational speed is kept constant at 750 rpm which analogues to engine speed equal to 1500 rpm. Rail pressure (which is strong indication to injection pressure) is varied from 1200 up to 1500 bar. Starting with high pressure pump, figures 20 and 21 shows the instantaneous normalized displacement and velocity of pump plungers relative to each other. To start injection process, logical control signals are generated by $E C U$ with the same sequence of firing order as shown in fig. 22. These signals fire the injectors solenoids accordingly. When control valve in each injector opens, pressure in control chamber falls rapidly as a result of fast discharge and throttled charge from the inlet orifice. This appears clearly in fig 23 at which the falling pressure pulse indicates to injection process. The figure shows also the relative pressure signal of each individual injector obeys the firing order. On the other hand fig 24 demonstrates 
the sequence of injection process starting from the logic control signal of injector No. 1. It is clear from the figure that when firing the solenoid, the current increased rapidly and strong magnetic field is then created. By the time, the armature affected by fast increase in magnetic force, and when it becomes greater than the spring tightening force it begins to move towards the solenoid. When armature approaches the solenoid, the inductance increases accordingly. This condition impedes the current for further growing. By the end of signal, the induced current diminishes the magnetic field rapidly and allowing the spring to close the control valve. The figure shows also the bounce of armature at the upper limiter and lower seat. During the opening period of control valve, the fuel in control chamber experience sharp falls as discussed previously. This allows the needle to move against spring force and start injection. Magnifying the rise period of armature and the corresponding needle lift, time lag is identified for both armature/control valve assembly and needle valve. The results indicate that, injection lag is slightly less than twice the armature/ valve time lag. In present model, the cumulative fuel injected each cycle is calculated as eq(45). Because of the effect of wave action, there is corresponding fluctuations in injection quantity. To obtain average value, calculations continue for several injection cycles and the averaged value is then calculated as in eq(46). When varying the injection period, corresponding increase in injection quantity is obtained. On the other hand, Rail pressure shows less significant effect on the injection quantity along the entire range of injection duration and rail pressure as shown in fig, 26. Although rising of the rail pressure may lead to improve atomization characteristics of the resultant spray.

When examining the effect of pump speed $\left(2^{\text {nd }}\right.$ case), the range from $500 \mathrm{rpm}$ up to 1250 is employed. This is equivalent to 1000 up to $2500 \mathrm{rpm}$ engine speed. The time lag for solenoid valve and needle valve to start their motion are calculated and plotted as shown in fig. 27. The time lag or the delay time of the solenoid is identified as the period between the appearances of control logic signal up to the beginning of armature motion. The delay in injection process is identified as the period between the control logic signal up to the beginning of injection as well. The delay in solenoid or injector may consider as a measure of system response. In this case study the injection period is kept constant at $1.11 \mathrm{~ms}$. Because all the rail pressure range lies beyond the allowable opening pressure of the injector, it was found that, rail pressure has no significant effect of injection lag. But it may has significant effect on valve motion and injection rate profile. The results show when increasing the pump speed, corresponding increase in time lag measured in pump cam angle is obtained. At $1250 \mathrm{rpm}$, the injection lag reaches 2.16 degree which equivalent to 4.32 degree on crank angle. This means that, for more accurate injection timing, injection advance must account the injection response time beside the delay period.

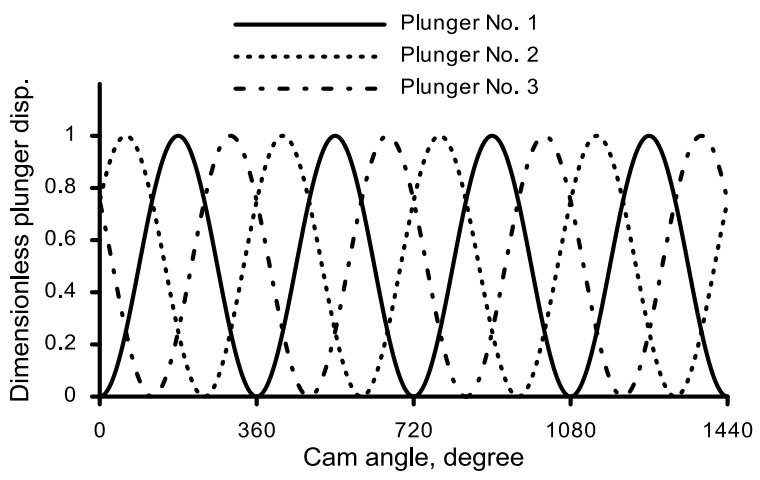

Figure 20 Instantaneous plunger displacement with respect to cam rotation.

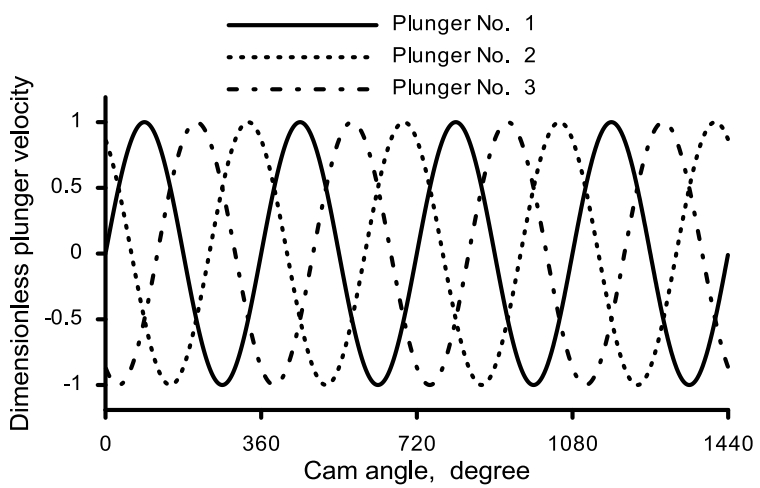

Figure 21 Instantaneous plunger velocity with respect to cam rotation.

$$
\begin{aligned}
& \left(m_{f}\right)_{c y c l e}=\oint \dot{m}_{f} \cdot d t \\
& \left(\bar{m}_{f}\right)_{c y c l e}=\frac{\sum\left(m_{f}\right)_{c y c l e}}{N O C}
\end{aligned}
$$


Safwat A. Wilson "Modeling Common Rail Fuel injection system in Diesel Engines"

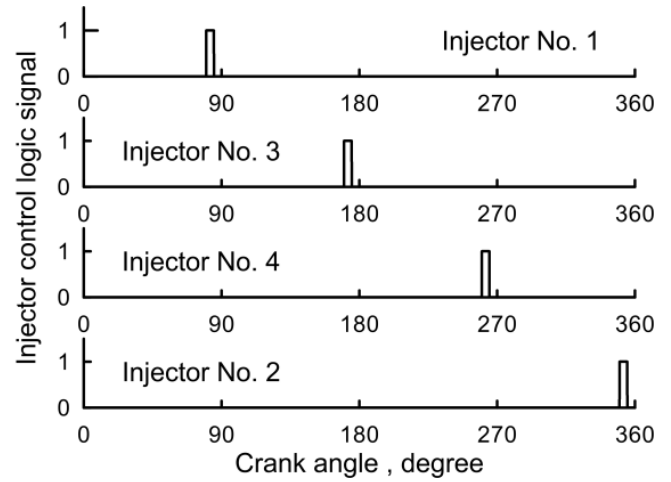

Figure 22 Logic diagram for injectors signal

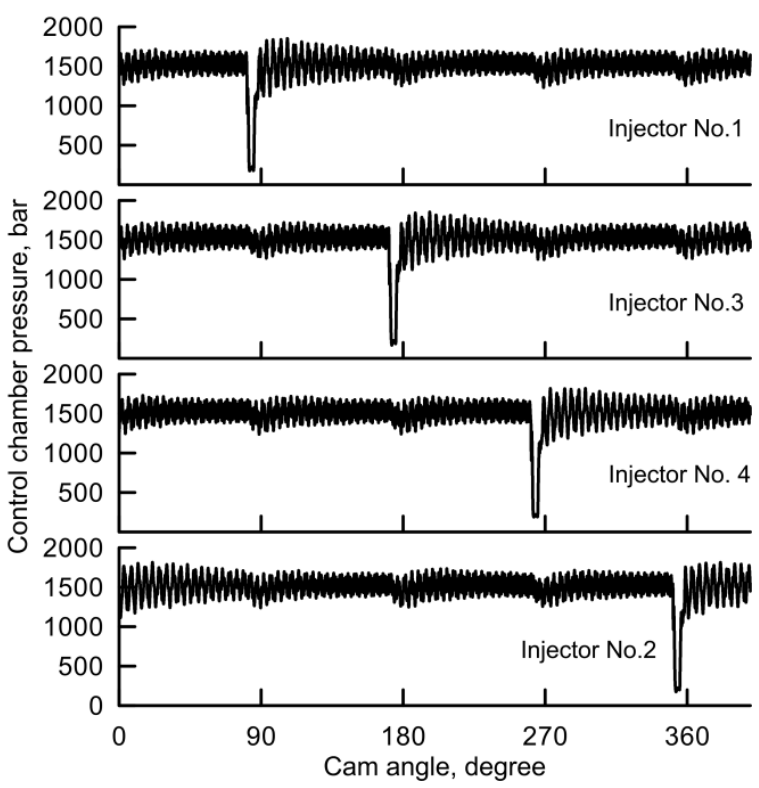

Figure 23 Pressure at injectors control chamber

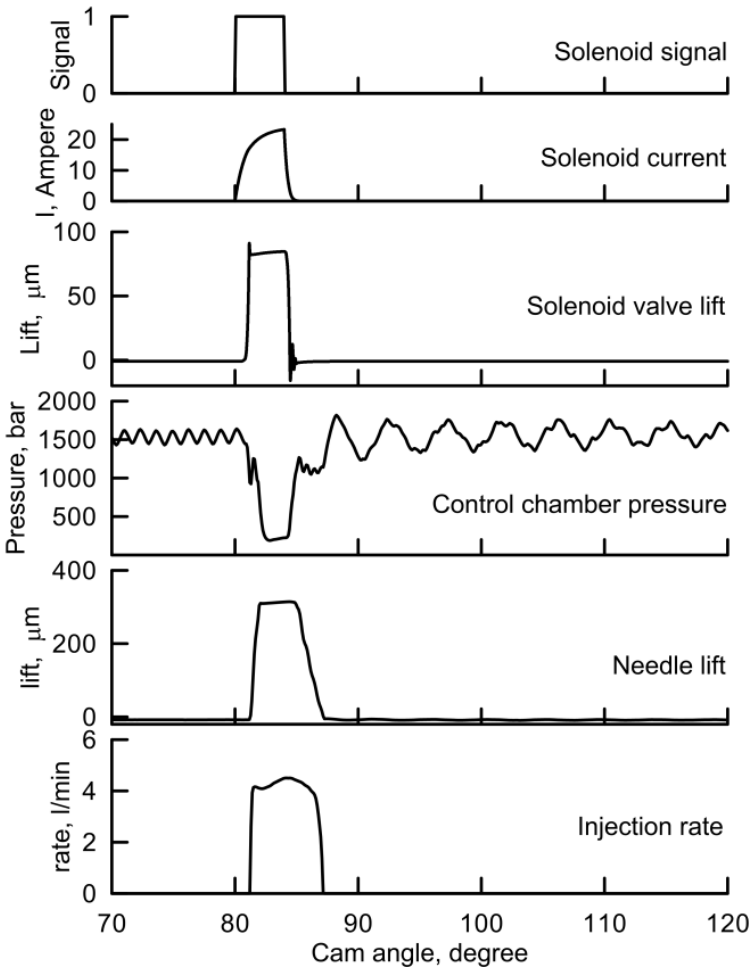

Figure 24 Injection events starting from injector signal up to injection rate at 1500 bar rail pressure, $750 \mathrm{rpm}$ pump rotational speed and injection duration $0.88 \mathrm{~ms}$. (injector No.1)

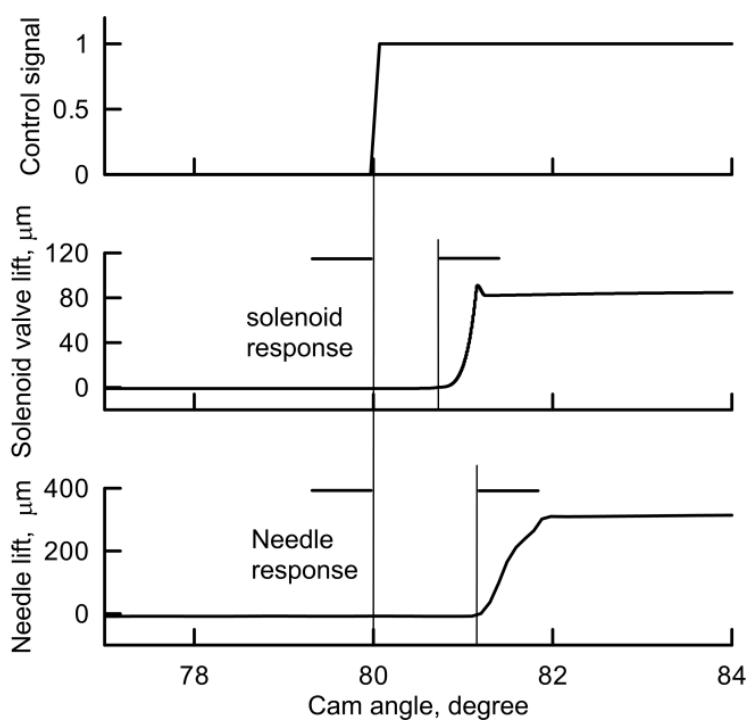

Figure 25 Response time of solenoid valve and needle valve. Pump speed $=750 \mathrm{rpm}, 1500$ bar Rail pressure and $1.11 \mathrm{~ms}$ injection duration. 


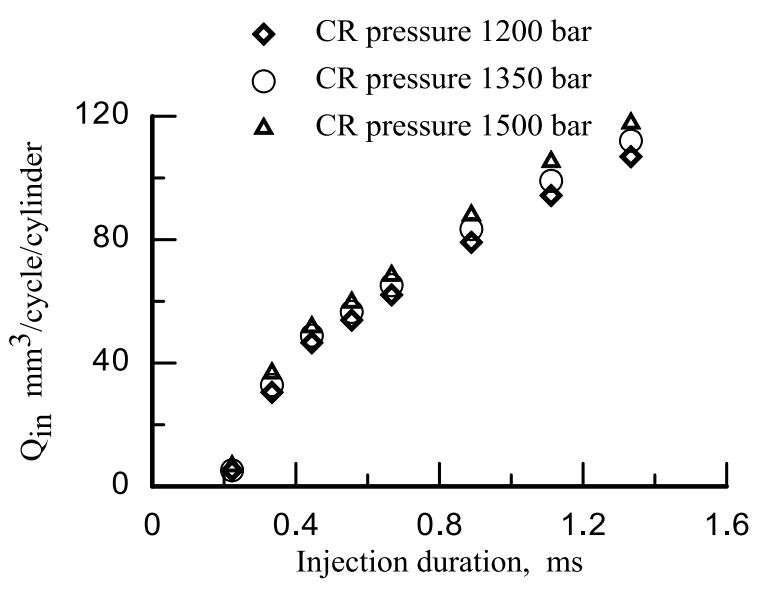

Figure 26 Effect of injection duration on quantity of fuel injected per cycle per cylinder at different rail pressure..

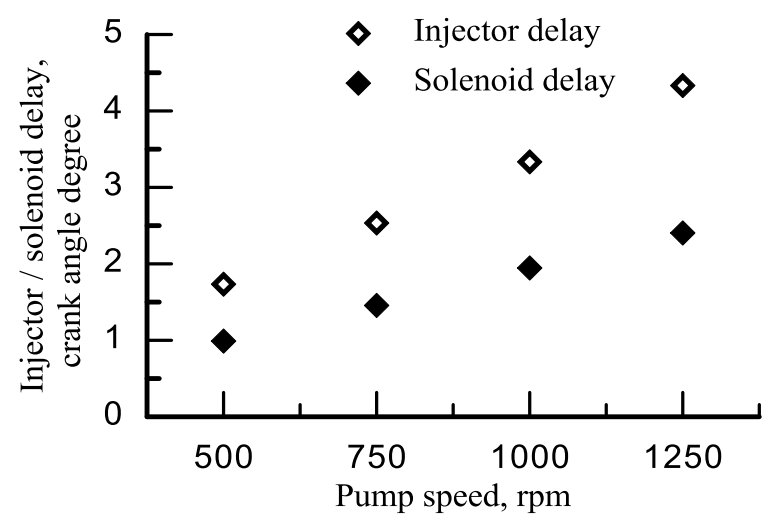

Figure 27 Effect of rotational speed on both solenoid delay and injector delay. Injection duration $1.11 \mathrm{~ms}$

\section{CONCLUSION}

A complete mathematical model is developed to simulate the physical process occurs inside electronically controlled version of common rail injection system. The model is capable to predict the pressure anywhere inside the hydraulic elements of the system as well as the injection rate. For more realistic representation, the model accounts multiple injectors and their pressure lines. Firing order is also considered via control signal sequences. Moreover, the dynamic representation of needle and valves motions, kinematics of plungers motion with respect to cam rotation are also included. The model takes into account the elastic deformation of valve seat and valve stroke limiter during the opening and closing process. The model also contains the simulation of electromagnetic force generated from solenoid. The model is validated by comparing the results with other model and experimental data. Comparison shows fair agreement. The model is then employed to figure out the behavior of injection system when running at different rail pressure. The response of electro-mechanical parts at different pump speeds is studied also. From present study, it is concluded that:

- Complete mathematical model is developed to simulate the behavior of electronically controlled common rail injection system for diesel engines. The model is validated by compared its results with experimental data and other model results [28].

- The model can predict the injection rate as well as the total amount of fuel injected per cycle per cylinder. Therefore, it can be used as sub-model when studying the structure of the diesel spray or simulating the in-cylinder combustion process.

- The model shows that, the total amount of fuel injected per cycle per cylinder to some extent is independent of rail pressure in the range of 1200 to 1500 bar.

- When examining the effect of pump speed on the injection delay, it was found that, increasing pump speed (from $500 \mathrm{rpm}$ up to $1250 \mathrm{rpm}$ ) leads to corresponding increase in injection delay. At $1250 \mathrm{rpm}$ pump speed, the injection delay becomes 2.16 degree on pump shaft, which equivalent to 4.32 degree on crank shaft scale. Therefore, injection delay must consider when assigning the injection timing accurately, especially for modern high speed diesel engines. This delay period contains the delay in solenoid valve. The results show that it almost half the total injection delay. Therefore, if fast injection response is needed (especially in multi stage injection), it is recommended to replace the solenoid valve by another actuator like piezo-crystal actuator.

\section{REFERENCES}

[1] Bunes O. and Einang P. M. "Comparing the Performance of the Common Rail Fuel Injection System with the Traditional Injection System Using Computer Aided Modelling and Simulation." International Conference on Marine Science and technology for Environmental Sustainability, Newcastle, September 2000.

[2] Abthoff J., Duvinage F., Kramer M., Paule M., "The 2-Stroke DI-Diesel Engine with Common Rail Injection for Passenger Car Application", SAE Paper No.98103, pp. 1-7, 1998

[3] Flaig U., Polach W. and Ziegler G. "Common Rail System (CR-System) for Passenger Car DI Diesel Engines; Experiences with Applications 
for Series Production Projects" SAE Paper No. 1999-01-0191,pp. 1-10, 1999.

[4] Rutland C. J., Ayoub N., Han Z., Hampson G., Kong S., Mather D., Montgomery D., Musculus M., Patterson M., Pierpont D., Ricart L., Stephenson P. and Reitz R. D. "Diesel Engine Model development and Experiments" SAE Paper No. 951200, pp. 1-19,1995.

[5] Rutland C. J., Ayoub N., Han Z., Hampson G., Kong S., Mather D., Musculus M., Patterson M., Ricart L., Stephenson P. and Reitz R. D. "Progress Towards Diesel Combustion Modeling" SAE Paper No. 952429, pp. 137149,1995 .

[6] Fettes C. Heimgartner C. and Leipertz A. "Evaluation of the Potential of Passenger Car Common Rail Injection by Simultaneous Application of In-Cylinder Fuel and Flame Detection" The fifth International Symposium and modeling of Combustion in Internal Combustion Engines, pp. 38-43, Nagoya, July 14, 2001

[7] Spegar T. D., Chang S., Das S., Norkin E. and Lucas R. "An Analytical and Experimental Study of a High Pressure Single Piston Pump for Gasoline Direct Injection (GDI) Engine Applications" SAE technical paper series No. 2009-01-1504, pp.1-11, 2009.

[8] Allocca L., Montanaro A. and Lucchini T. "Experimental and Numerical Characterization of High Pressure Sprays for GDI Engines." DIPSI Workshop 2011 on Droplet Impact Phenomena \& Spray Investigation, Bergamo, Italy, May 27, 2011.

[9] Gaeta A., Fiengo G., Palladino A. and Giglio A. "Design and Experimental Validation of a Model Based Injection Pressure Controller in a Common Rail System for GDI Engine." American Control Conference on O'Farrell Street, San Francisco, CA, USA, pp. 52735278, June 29 - July 01 , 2011

[10] Masataka A. and Kenji A. "Dynamic Behavior of Multi-Stage Injection Diesel Spray" SAE Technical paper series No. 970044, pp.1-9, 1997.

[11] Su T.F.,Patterson M. A., Reitz R. D. and Farrell P. V. "Experimental and numerical Studies of High Pressure Multiple Injection Sprays" SAE Technical paper series No. 960861, pp.93-104, 1996.

[12] Tennison P. J.,Georjon T. L., Farrell P. V. and Reitz R. D. "An Experimental and Numerical
Study of Sprays from a Common Rail Injection System for Use in an HSDI Diesel Engine" SAE Technical paper series No. 980810, pp.93-107, 1998.

[13] Lee C. S. and Park S. W. "An Experimental and Numerical Study on Fuel Atomization Characteristics of high-Pressure Diesel Injection Sprays" Fuel, 81, pp.2417-2423, 2002

[14] Tanaka T., Ando A. and Ishizaka K. "Study on Pilot Injection of DI Diesel Engine Using Common-Rail Injection System" JSAE Review, 23, pp.297-302, 2002.

[15] Doudou A. "Turbulent Flow Study of an Isothermal Diesel Spray Injected by a Common Rail System" Fuel 84, pp.287-298, 2005

[16] Kong S., Ricart L. M. and Reitz R. D. "InCylinder Diesel Flame Imaging Compared with Numerical Computations" SAE Technical paper series No. 950455, pp.129-153, 1995.

[17] Han Z., Uludogan A., Hampson G. J. and Reitz R. D. "Mechanism of Soot and Nox Emission reduction Using Multiple-Injection in a Diesel Engine" SAE Technical paper series No. 960633, pp.1-19, 1996.

[18] Ricart L. M. and Reitz R. D. "Visualization and Modeling of Pilot Injection and Combustion in Diesel Engines" SAE Technical paper series No. 960833, pp.237-256, 1996.

[19] Ayoub N. S. and Reitz R. D "Multidimensional Modeling of Fuel Effects and Split Injections on Diesel Engine Cold-Starting" AIAA Journal of Propulsion and power, Vol. 13, No. 1, pp. 123130, January-February 1997

[20] Reitz R. D. "Controlling D.I. Diesel Engine Emissions Using Multiple Injections and EGR" Combustion Sci. and Tech., Vol. 138, pp. 257278, 1998.

[21] Bakenhus M. and Reitz R. D. "Two-Color Combustion Visualization of Single and Split Injections in a Single-Cylinder Heavy Duty D.I. Diesel Engine Using an Endoscope-Based Imaging System" SAE Technical paper series No. 1999-01-1112, pp.121-138, 1999.

[22] Choi C. Y., Bower G. R. and Reitz R. D "Effect of Biodiesel Blended Fuels and Multiple Injection on D.I. Diesel Engines" SAE Technical paper series No. 970218, pp.1-20, 1997.

[23] Boulouchos K. and Stebler H "Combustion Features and Emissions of a DI-Diesel Engine with Air Path Optimization and Common Rail 
Fuel Injection" series No. 981931, pp.1-11, 1998.

[24] Montgomery D. T. Chan M. Chang C. T. Farrell P. V. and Reitz R. D. "Effect of Injector Nozzle Hole Size and Number on Spray characteristics and the Performance of a Heavy Duty D. I. Diesel Engine" SAE Technical paper series No. 962002, pp.1-17, 1996.

[25] Gobert K., Barkhimer R. L., Beck N. J., Wickman D. D., Tanin K. V. Das T. D. and Reitz R. D. "An Evaluation of Common Rail, Hydraulically Intensified Diesel Fuel Injection System Concept and rate Shapes", SAE Technical paper series No. 981930, pp.1-23, 1998.

[26] Hayat Q., Li-Yun F. , Xiuzhen M. and Bingqi T. "Comparative Study of Pressure Wave Mathematical Models for HP Fuel Pipeline of CEUP at Various Operating Conditions" International Journal on Smart Sensing and Intelligent Systems Vol. 6, No. 3, pp.10771101, June 2013

[27] Hayat Q., Liyun F., Enzhe S., Xiuzhen M., Bingqi T. and Farouk N. "Analysis of Diesel and Rapeseed Methyl Ester Properties in CEUP Fuel Pipeline Using Frequency Dependent Damping Model" International Journal on Smart Sensing and Intelligent Systems Vol. 7, No. 2, pp.498-518, June 2014

[28] Bingqi T., Liyun F., Xiuzhen M., Hayat Q., Yun B. and Yang L. " Investigation of Main Injection Quantity Fluctuation due to Pilot Injection in High Pressure Common Rail Fuel Injection System" International Journal on Smart Sensing and Intelligent Systems Vol. 7, No. 2, pp.820-836, June 2014

[29] Fox J. G. and Mahanty J. "The Effective Mass of an Oscillating Spring" American. Journal of Phys., Vol. 38, Issue 1., 1970.

[30] Kekedjian H. and Krepec T. "Further Development of Solenoid Operated Gas Injectors with Fast Opening and Closing" SAE Paper No.940450, pp. 73- 84, 1994

[31] Fitzgerald A. E. and Kingsley C. "Electrical Machinery-The Dynamics and Statics of Electromechanical Energy Conversion" McGraw Hill Book Co., $2^{\text {nd }}$ Edition, 1961.

[32] Wilson S. A. " Behavior of Diesel Fuel Injection System When Running with Biodiesel" ERJ, Menoufiya University, Vol. 30, No.2, pp. 89-103, April 2007.

[33] Douglas J. F., Gasiorek J. M. and Swaffield G. A. "Fluid Mechanics" Pitman Pub. Ltd, ch. 8 , pp. 243-281, 1981.
[34] Heywood J. B. "Internal Combustion Engine Fundamentals" McGraw Hill., international edition, pp. 760, 1988.

\section{NOMENCLATURE}

A Cross section area of solenoid core

$A_{c} \quad$ Conical cross section area

$A_{\text {o.il }}$ Orifice area of control chamber

a Sonic speed

$a_{g} \quad$ Solenoid/armature air gap

$C$ Damping coefficient

$d_{v} \quad$ Valve port diameter

$e \quad$ Cam eccentric

$F_{l} \quad$ Stroke limiter reaction force

$F_{p} \quad$ Pressure force

$F_{S} \quad$ Seat reaction force

$h$ Instantaneous plunger lift

$h_{o} \quad$ Plunger lift at no load condition

$K \quad$ Bulk modulus

$k_{a} \quad$ Armature spring stiffness

$k_{d} \quad$ Delivery valve spring stiffness

$k_{l} \quad$ Valve limiter stiffness

$k_{n} \quad$ Needle spring stiffness

$k_{s} \quad$ Valve seat stiffness

$L \quad$ Inductance

$l_{r} \quad$ Load ratio (0-1) (no load-full load)

$l_{r l} \quad$ Length of common rail line $m$

$l_{i l} \quad$ Length of injection line $m$

$l_{z} \quad$ Slant length of the cone $m$

$m_{d} \quad$ Effective mass of delivery valve $\quad \mathrm{kg}$

$N \quad$ Number of turns in solenoid coil

$N_{c} \quad$ Cam shaft rotational speed

$n_{p} \quad$ No. of plungers in pump unit

$P_{p} \quad$ Pressure in pump barrel

$P_{v} \quad$ Pressure in valve chamber

$P_{d} \quad$ Pressure in delivery chamber

$\dot{Q}_{v} \quad$ Fuel flow rate out of valve chamber

$m^{2}$

$m^{2}$

$m^{2}$

$\mathrm{m} / \mathrm{s}$

$m$

N. $s / m$

$m$

$m$

$N$

$N$

$N$

$m$

$m$

M.Pa

$N / m$

$N / m$

$N / m$

$N / m$

$N / m$

$m$

$m$
$k g$

rpm

$P a$.

$P a$.

$P a$.

$\mathrm{m}^{3} / \mathrm{s}$

$r \quad$ Ball radius

$s \quad$ Pump plunger stroke

$m$

$m$

$m$

$s_{e} \quad$ Pump plunger effective stroke

$s_{e o} \quad$ Effective stroke at no load

$t$ Time

$u \quad$ Fuel velocity through lines

$V_{d} \quad$ Volume of delivery chamber

$x \quad$ Axial coordinate

$Z \quad$ Delivery valve lift

$\dot{Z} \quad$ Instantaneous valve velocity

$Z_{a} \quad$ Armature valve lift

$Z_{n} \quad$ Injector needle lift

\section{Greek letters}

$\Delta \quad$ Plunger / barrel clearance $m$

$\theta \quad$ Cam shaft rotation angle deg.

$\theta_{i p} \quad$ Cam angle when closing FMV deg

$\theta_{s} \quad$ Valve seat angle deg.

$v_{f} \quad$ Kinematic viscosity of the fuel $\quad \mathrm{m}^{2} / \mathrm{s}$ 
$\mu_{f} \quad$ Dynamic viscosity of the fuel $\quad \mathrm{Ns} / \mathrm{m}^{2}$

\section{Abbreviations}

BSFC Brake specific fuel consumption

bos Beginning of stroke

CEUP Combination Electronic Unit Pump

DI Direct injection

$E C U$ Electronic control unit

EGR Exhaust gas recirculation

eos End of stroke

FMV Fuel metering valve

HPCR High pressure common rail

H.P.P High pressure pump

$i \quad$ Injection

il Injection line

L.P.P Low pressure pump

P.F Primary filter

$r \quad$ Common rail line

S.F Secondary filter

$S M D$ Sauter mean diameter

$s \quad$ Stroke

TTL Transistor/transistor logic

$$
\text { subscript }
$$

a Armature

$d \quad$ Delivery valve

$n \quad$ Needle valve

Appendix A.

Table (A1) Technical data of

Bosh HPCR system [28]

\begin{tabular}{|c|c|c|}
\hline component & parameter & value \\
\hline \multirow{2}{*}{$\begin{array}{l}\text { Supply } \\
\text { pump }\end{array}$} & $\begin{array}{l}\text { Supply rate of supply } \\
\text { pump }\end{array}$ & $5 \mathrm{l} / \mathrm{min}$ \\
\hline & $\begin{array}{l}\text { Relief valve open } \\
\text { pressure }\end{array}$ & $0.4 M P a$. \\
\hline \multirow{2}{*}{$\begin{array}{l}\text { High } \\
\text { pressure } \\
\text { pump }\end{array}$} & Plunger diameter & $6 \mathrm{~mm}$ \\
\hline & Cam lift & $9 \mathrm{~mm}$ \\
\hline \multirow{3}{*}{$\begin{array}{l}\text { Common } \\
\text { rail }\end{array}$} & $\begin{array}{l}\text { Common rail inner } \\
\text { diameter }\end{array}$ & $9.5 \mathrm{~mm}$ \\
\hline & Common rail volume & $21.5 \mathrm{ml}$ \\
\hline & $\begin{array}{l}\text { Limited valve open } \\
\text { pressure }\end{array}$ & $220 \mathrm{MPa}$ \\
\hline \multirow{4}{*}{$\begin{array}{l}\text { High } \\
\text { pressure } \\
\text { pipe }\end{array}$} & Length (pump to rail) & $320 \mathrm{~mm}$ \\
\hline & $\begin{array}{l}\text { Inner diameter (pump } \\
\text { to rail) }\end{array}$ & $3 \mathrm{~mm}$ \\
\hline & Length (rail to injector) & $300 \mathrm{~mm}$ \\
\hline & $\begin{array}{l}\text { Inner diameter (rail to } \\
\text { injector) }\end{array}$ & $2.5 \mathrm{~mm}$ \\
\hline \multirow[t]{4}{*}{ Injector } & Control valve lift & $0.08 \mathrm{~mm}$ \\
\hline & $\begin{array}{l}\text { Diameter of inlet } \\
\text { orifice }\end{array}$ & $0.24 \mathrm{~mm}$ \\
\hline & $\begin{array}{l}\text { Diameter of outlet } \\
\text { orifice }\end{array}$ & $0.27 \mathrm{~mm}$ \\
\hline & Needle lift & $0.3 \mathrm{~mm}$ \\
\hline
\end{tabular}

